\title{
Organic Montmorillonite Intercalated Nano-composites Prevent Post-Surgical Associated Infections
}

\author{
Zahra Rezvani', Mazaher Gholipourmalekabadi², Saeid Kargozar³, Peiman Brouki Milan², \\ Masoud Mozafari ${ }^{2, *}$ \\ ${ }^{1}$ Department of Chemistry, Materials and Chemical Engineering “Giulio Natta”, Politecnico di Milano, Milano, Italy \\ 2Department of Tissue Engineering \& Regenerative Medicine, Faculty of Advanced Technologies in Medicine, Iran \\ University of Medical Sciences, Tehran, Iran \\ ${ }^{3}$ Tissue Engineering Research Group (TERG), Department of Anatomy and Cell Biology, School of Medicine, \\ Mashhad University of Medical Sciences, Mashhad, Iran
}

*Corresponding authors: E-mail: mozafari.masoud@gmail.com

DOI: $10.5185 /$ amlett.2020.021471

In this study, organic montmorillonite (OMMT) is a modified form of montmorillonite (MMT) in which chitosan (CS) intercalated MMT by ion exchange of sodium ions from $\mathrm{Na} / \mathrm{MMT}$ with $-\mathrm{NH}_{3}{ }^{+}$of CS. The structural analysis confirmed intercalation of CS into MMT layers, indicating that CS molecular chains incorporated into the MMT layers. The interlayer distance of the MMT layered was $1.128 \mathrm{~nm}$ and in the OMMT layers enlarged to $2.365 \mathrm{~nm}$. Antibacterial activity analysis showed that unmodified MMT could not inhibit the growth of bacteria. Nevertheless, after addition of the CS molecules, an increase in the interlayer distance of MMT was observed. No difference was observed between the viability of the human dental pulp stem cells (hDPSCs) contacted to different concentrations (ranging from 0.5 to $2 \mathrm{mg} / \mathrm{ml}$ ) of MMT and OMMT in all time intervals, when compared with the control samples. Furthermore, neither MMT nor OMMT showed apoptosis and cytotoxicity effect on the cells. The strong antibacterial activity of the synthesized OMMT nanocomposite was also confirmed against $E$. coli, $S$. aureus, $K$. pneumonia and $P$. aeruginosa, suggesting its high potential for the prevention of post-surgical infections.

\section{Introduction}

Recently, polymer/clay composites have received much more attention since they showed enhanced characteristics such as conductivity, dye adsorption and antibacterial activity. Chitosan (CS), the second most abundant natural polymer is the deacetylation form of chitin [1]. CS has shown remarkable properties such as biocompatibility, biodegradability, non-toxicity, antimicrobial activity. It is a cationic biopolymer that can be intercalated in silicate layers of montmorillonite (MMT) by ion exchange and hydrogen bonding processes [2]. Its chemical structure is consisted of two different silica tetrahedral sheets among which an octahedral sheet of aluminum or magnesium hydroxide and an interlayer district containing $\mathrm{Ca}^{2+}$ or $\mathrm{Na}^{+}$ can be incorporated [3]. MMT is widely used in adsorption, composites and nanocomposites $[\mathbf{1 , 4 ]}$. Based on the intercalation between CS molecular chains and silicate layers the resulting layered nanocomposites exhibit significant structural and functional properties, this intercalation also enhanced the physico-chemical features of nanocomposite [2]. Therefore, such nanocomposites could have potential applications in medicine, drug delivery, tissue engineering and etc. [3,5]. Annually, a large number of patients affected by post-surgical infections, leading to serious mortality and financial losses for health systems and patients. According to above mentioned, organic montmorillonite (OMMT) nanocomposites expected to be a good candidate for the prevention of this type of infections for tissue engineering applications.

\section{Preparation of CS/MMT composite}

The CS/MMT composites were synthesized through an ionexchange reaction using a version of the technique explained by Kabiri et al. 2007 [4]. For this purpose, a gram of MMT powder was dispersed in $50 \mathrm{ml}$ deionized water under magnetic stirring for $2 \mathrm{hr}$ and two grams of CS separately dissolved in $312 \mathrm{ml}$ of a low concentration solution of acetic acid with the same condition. After that, CS solution slowly added to MMT solution then mixture solution stirred for $4 \mathrm{hr}$ at $60^{\circ} \mathrm{C}$. After the heat treatment and purification with a centrifuge, the precipitant was washed several times in deionized water. The product dried in an oven at $80^{\circ} \mathrm{C}$ for $6 \mathrm{hr}$.

\section{Characterization}

The Fourier transform infrared (FTIR) (PerkinElmer Spectrum 400) analysis was used to characterize the functional groups of the samples. In addition, it showed the reaction between CS and MMT. The X-ray diffraction (XRD) using a Philips-PW-1800 devise with copper anode $\left(\lambda=1.54^{\circ} \mathrm{A}\right)$ was utilized to characterize the clay dispersion process in the polymer matrix. The basal spacing value 


\section{Advanced Materials Letters www. vbripress.com/aml}

$\left(d_{001}\right)$ of the MMT and OMMT samples were computed using Bragg equation $(\mathrm{n} \lambda=2 \mathrm{~d} \sin \Theta)$.

The effects of MMT and OMMT on the activity of human dental pulp stem cells (hDPSCs) were determined by MTT and LDH activity assays. Effects of MMT and OMMT on apoptosis and necrosis of the hDPSCs were also determined by flowcytometry using Annexin V kit (Biovision, Mountain View, CA) to better evaluate the samples, a control sample was also selected (culture plate).

In addition, the antibacterial activity of the prepared samples against four ATCC bacteria ( $P$. aeruginosa, $S$. aureus, E. coli and $K$. pneumonia) was determined by the Kirby-Bauer disk diffusion test [7] according to Clinical Laboratory Standards Institute (CLSI) 2013 guidelines [6].
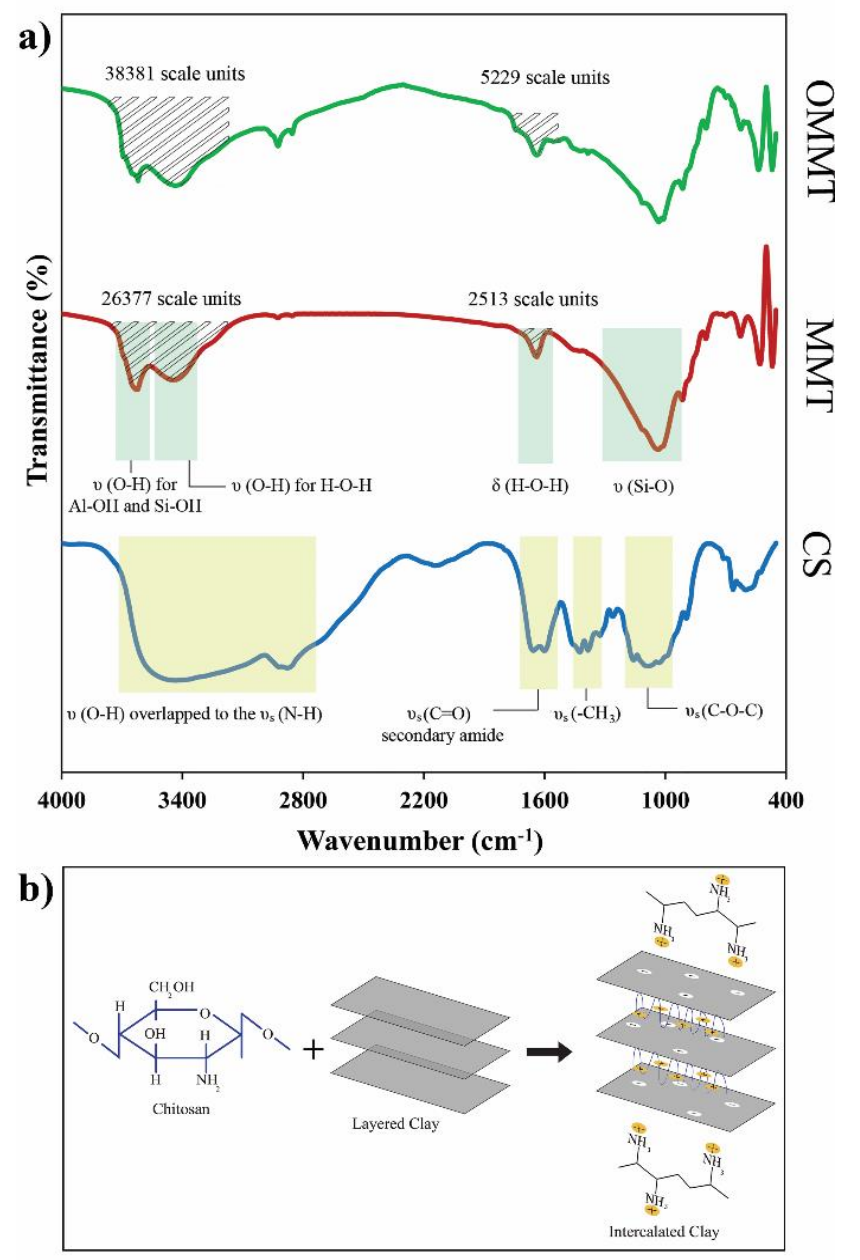

Fig. 1. (a) FTIR spectra of CS, MMT and OMMT. (b) The schematic of modification MMT by CS

\section{Results and discussion}

The interaction of CS and MMT can be shown in Fig. 1a. The leading bands in the CS spectrum were basically as a result of stretching vibrations of $\mathrm{OH}$ groups at $3437 \mathrm{~cm}^{-1}$. These peaks are partially overlapped to the associated $\mathrm{N}-\mathrm{H}$ groups. The peak observed at $2878 \mathrm{~cm}^{-1}$ corresponded to $\mathrm{C}-\mathrm{H}$ band in $\mathrm{CH}_{2}$ symmetric and asymmetric stretching vibration. In addition, the bond in the range of (1600-1656) $\mathrm{cm}^{-1}$ could be associated to the vibrations of carbonyl groups $(\mathrm{C}=\mathrm{O})$ presented in the secondary amide groups $[\mathbf{8}]$. Absorption in the range of $1261 \mathrm{~cm}^{-1}$, (1082-1158) $\mathrm{cm}^{-1}$ were showed $(\mathrm{C}-\mathrm{O}-\mathrm{H})$ and (C-O-C) stretching vibration in CS. In the MMT spectra, the specific band at $3622 \mathrm{~cm}^{-1}(\mathrm{O}-\mathrm{H})$ was dedicated to the stretching vibration of $\mathrm{Al}-\mathrm{OH}$ and $\mathrm{Si}-\mathrm{OH}$, also, at $3448 \mathrm{~cm}^{-1}(\mathrm{O}-\mathrm{H})$ to the stretching vibration of $\mathrm{H}_{2} \mathrm{O}$. The peak was observed at $1639 \mathrm{~cm}^{-1}(\mathrm{H}-\mathrm{O}-\mathrm{H})$ is related to $\mathrm{H}_{2} \mathrm{O}$ [8], [9]. Absorption in the range of $1035 \mathrm{~cm}^{-1}, 915 \mathrm{~cm}^{-1}$, $799 \mathrm{~cm}^{-1}$ and $529 \mathrm{~cm}^{-1}$ showed the stretching vibration of $\mathrm{Si}-$ $\mathrm{O}$ and related $(\mathrm{Al}-\mathrm{Al}-\mathrm{OH}),(\mathrm{Al}-\mathrm{Fe}-\mathrm{OH})$ and $(\mathrm{Al}-\mathrm{Mg}-\mathrm{OH})$ groups, respectively. Based on this analysis, absorption band at $3437 \mathrm{~cm}^{-1}$ corresponded to the overlapping of $\mathrm{O}-\mathrm{H}$ and $\mathrm{N}-\mathrm{H}$ functional groups bands in CS, obviously shifted to lower wave numbers. In addition, the intensity of the absorption band at $1035 \mathrm{~cm}^{-1}$ related to $\mathrm{Si}-\mathrm{O}$ of MMT decreased. The area in the range of $3200-3600 \mathrm{~cm}^{-1}$ and $1500-1700 \mathrm{~cm}^{-1}$ increased in OMMT from 26377 to 38381 and 2513 to 5229 scale units, respectively (Fig.1 (a)). These results demonstrated the intercalation between $\mathrm{CS}$ and MMT. It was expected that $-\mathrm{NH}_{3}{ }^{+}$groups of $\mathrm{CS}$ could effectively cooperate electrostatically with the negatively charged groups in the MMT, shown in (Fig. 1(b)). This phenomenon confirms that an ionic exchange reaction occurred between $\mathrm{CS}$ and $\mathrm{Na} / \mathrm{MMT}$ and that consequently CS was intercalated into the MMT layers [3,9].

The interlayer expansion or d-spacing of unmodified MMT and OMMT was determined by XRD, shown in Fig. 2a. The typical diffraction pattern of the MMT sample was at around $7.8^{\circ}(\mathrm{d}$-spacing $=1.128 \mathrm{~nm})$. By adding CS to MMT composite the diffraction peak of MMT shifted to a lower angel $2 \Theta=3.7^{\circ}(\mathrm{d}$-spacing $=2.365 \mathrm{~nm})$ that showed the intercalated structure, based on the Bragg equation $(\mathrm{n} \lambda=2 \mathrm{~d} \sin \Theta)$ when the peak shifted to a low angle the $\mathrm{d}-$ spacing increased simultaneously $[\mathbf{1 , 8}]$. This increase in $\mathrm{d}$ spacing proved that CS molecular chains incorporated between the interlayer of MMT by an ionic exchange reaction. This considerable intercalated structure has been prepared due to the good compatibility of CS with $\mathrm{Na} / \mathrm{MMT}$. This compatibility was caused mostly through an ion exchange interaction between the sodium ions of the $\mathrm{Na} / \mathrm{MMT}$ and the $-\mathrm{NH}_{3}{ }^{+}$groups of CS molecules [3].

Due to the presence of amino and hydroxyl groups in the molecular structure of CS, hydrogen bonds can be formed when incorporated with the MMT structure that can further lead a strong interaction (see Fig. 1(b)).

The MTT and LDH results showed that there was no difference between the viability of the hDPSCs exposed to MMT and OMMT in all time intervals, when compared with control (Fig. 2b). Furthermore, neither MMT nor OMMT showed any cytotoxicity effects on the cells (Fig. 2c). The hDPSCs have shown to be an excellent cell source for cell therapy, especially in neural and bone tissue engineering. 
(a)

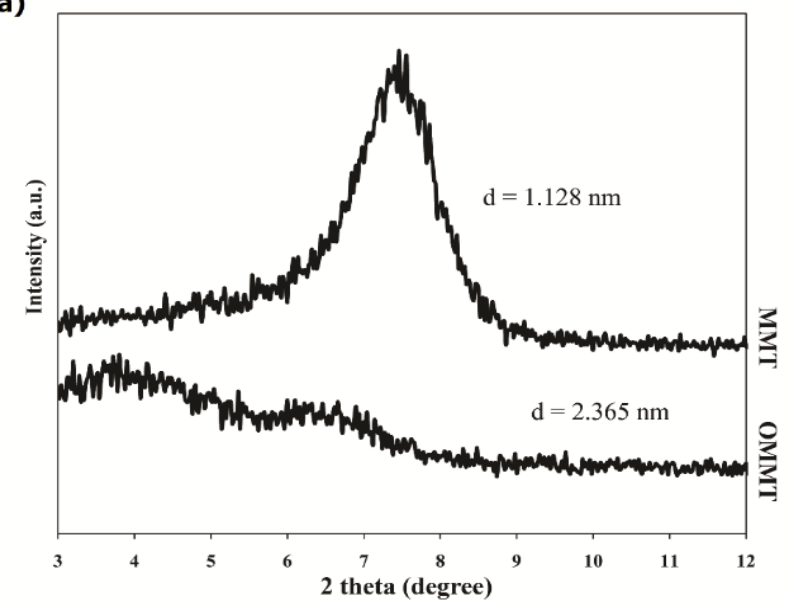

(b)

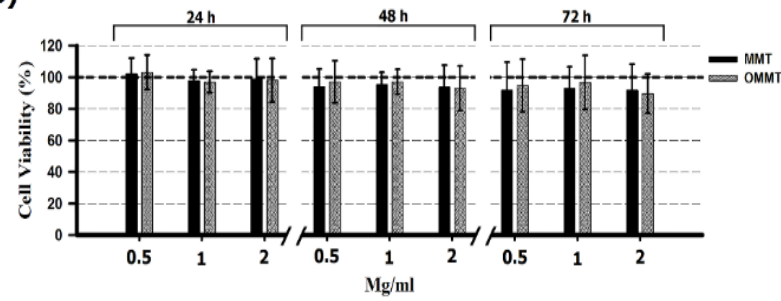

(c)

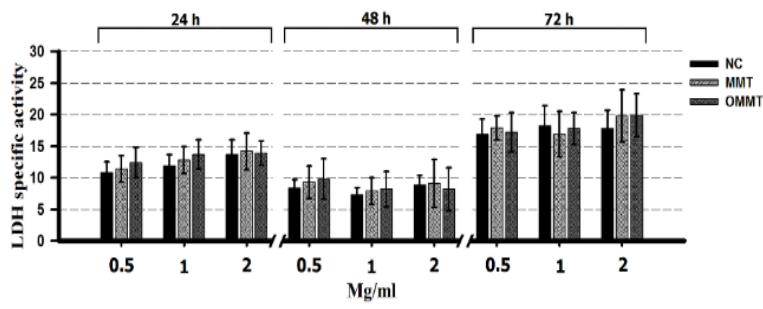

Fig. 2. (a) XRD patterns of MMT and OMMT. (b) MTT and (c) LDH specific activity assays for the cells exposed to $0.5,1$ and $2 \mathrm{mg} / \mathrm{ml}$ of MMT and OMMT for 24,48 and $72 \mathrm{~h}$ incubation in cell culture incubator.

The results obtained from apoptosis assay are shown in Fig. 3. There was no difference between the percentage of apoptotic cells in MMT (96.06 \pm 3.81$)$, OMMT (90.59 \pm $6.20)$ and control $(95.88 \pm 4.99)$. Both MMT and OMMT showed to have no significant effects on cell death and apoptosis when exposed to hDPSCs.
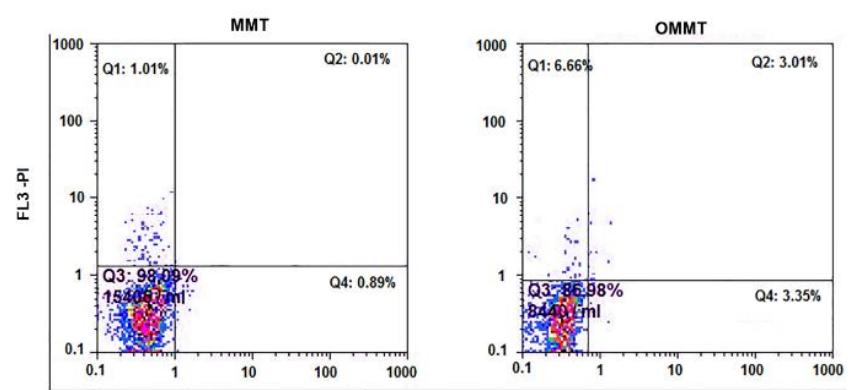

Fig. 3. Flow cytometry results of apoptosis in hDPSCs when exposed to MMT and OMMT.

The antibacterial function of both MMT and OMMT samples was evaluated by disc diffusion test and the results are shown in Fig. 4. As is clearly shown, the MMT samples did not show any detectable antibacterial activity against the tested bacteria. In OMMT, however, the CS endowed a favorable antibacterial property to the resulted construct. The diameters of the inhibition zones around the samples are listed in Table 1. Yang-Su Han et.al has reported that antimicrobial activity CS/Clay nanocomposites could show strong antimicrobial activates [2]. It is well known that CS itself has antibacterial activity according to its cationic ($\mathrm{NH}_{3}{ }^{+}$) group. So then, OMMT nanocomposites show the synergic effect because the CS molecular chains are equally diffused through the MMT layers.

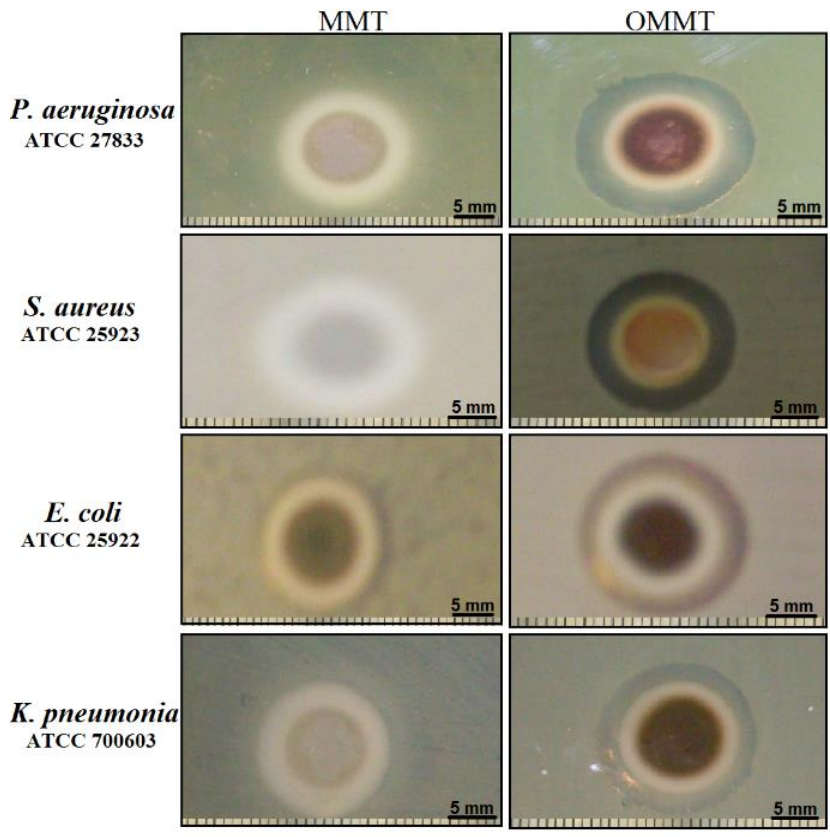

Fig. 4. Photograph of antibacterial activity of MMT/OMMT samples against four standard strains of bacteria.

As a result, OMMT nanocomposites showed improvement in antibacterial activity. E. coli, P. aeruginosa and $\mathrm{K}$. pneumonia, as the most significant gram-negative bacteria are responsible for more than $80 \%$ of all nosocomial infections $[\mathbf{1 0 , 1 1}]$. Furthermore, S. aureus is a gram-positive bacterium that can act as a key player in the post-surgical infections [12].

\section{Conclusion}

In this study, OMMT nanocomposites were prepared via a modified cationic exchange reaction. The results demonstrated that dispersion of CS chains in the nanocomposites happened through layer-by-layer mechanism. The antibacterial analysis showed that CS could enhance the antibacterial properties of MMT. This study also suggest the potential of OMMT nanocomposites in variety fields of medicine, drug delivery, wound dressing, tissue engineering, when the prevention of post-surgical infections is essentially needed. 


\section{Advanced}

Table 1. Antibacterial property of MMT and OMMT samples against four standard strains of bacteria as well as the mean and maximum size of inhibition zone.

\begin{tabular}{|c|c|c|c|c|c|c|}
\hline \multicolumn{4}{|c|}{ MTT } & \multicolumn{2}{|c|}{ OMTT } & \\
\hline Bacterial strain & $\begin{array}{c}\text { Plates with } \\
\text { inhibition zone } \\
(\%)\end{array}$ & $\begin{array}{c}\text { Mean } \\
\text { inhibition } \\
\text { zone }^{*}(\mathrm{~mm})\end{array}$ & $\begin{array}{c}\text { Max } \\
\text { inhibition } \\
\text { zone* }(\mathrm{mm})\end{array}$ & $\begin{array}{l}\text { Plates with } \\
\text { inhibition zone } \\
(\%)\end{array}$ & 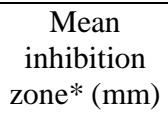 & $\begin{array}{l}\text { Max inhibition } \\
\text { zone* }(\mathrm{mm})\end{array}$ \\
\hline $\begin{array}{c}\text { E. coli } \\
\text { (ATCC 25922) }\end{array}$ & $\begin{array}{c}0 \\
\left(10^{\mathrm{a}}, 0^{\mathrm{b}}\right)\end{array}$ & 0 & 0 & $\begin{array}{c}100 \\
\left(10^{\mathrm{a}}, 10^{\mathrm{b}}\right)\end{array}$ & 7 & 8 \\
\hline $\begin{array}{c}\text { S. aureus } \\
\text { (ATCC 25923) }\end{array}$ & $\begin{array}{c}0 \\
\left(10^{\mathrm{a}}, 0^{\mathrm{b}}\right)\end{array}$ & 0 & 0 & $\begin{array}{c}100 \\
\left(10^{\mathrm{a}}, 10^{\mathrm{b}}\right)\end{array}$ & 6 & 8 \\
\hline $\begin{array}{c}\text { P. aeruginosa } \\
\text { (ATCC 27853) }\end{array}$ & $\begin{array}{c}0 \\
\left(10^{\mathrm{a}}, 0^{\mathrm{b}}\right)\end{array}$ & 0 & 0 & $\begin{array}{c}100 \\
\left(10^{\mathrm{a}}, 10^{\mathrm{b}}\right)\end{array}$ & 10 & 11 \\
\hline $\begin{array}{c}\text { K. pneumonia } \\
\text { (ATCC } \\
\mathbf{7 0 0 6 0 3 )}\end{array}$ & $\begin{array}{c}0 \\
\left(10^{\mathrm{a}}, 0^{\mathrm{b}}\right)\end{array}$ & 0 & 0 & $\begin{array}{c}100 \\
\left(10^{\mathrm{a}}, 10^{\mathrm{b}}\right)\end{array}$ & 6 & 7 \\
\hline
\end{tabular}

*Diameter of inhibition zone - Diameter of amniotic membrane sample.

${ }^{a}$ The number of plates examined for elimination of bacterial growth.

$\mathrm{b}$ The number of plate with inhibition zone or elimination.

\section{Keywords}

Montmorillonite, microstructure, post-surgical infections, tissue engineering.

Received: 24 October 2019

Revised: 18 December 2019

Accepted: 23 December 2019

\section{References}

1. Kpogbémabou, D.; Gridi-Bennadji, F.; Hoang, L. C.; Ghilardi, S.; Jacquet, A.; Smith, A.; Peyratout, C.; J. Colloid Interface Sci., 2014, 417, 152.

2. Han, Y. S.; Lee, S. H.; Choi, K. H.; Park, I.; J. Phys. Chem. Solids; 2010, 71, 464.

3. Lertsutthiwong, P.; Noomun, K.; Khunthon, S.; Limpanart, S.; Prog. Nat. Sci. Mater. Int.; 2012, 22, 502.

4. Z. M. M. J.; Kabiri, K.; Mirzadeh, H.; Iran. Polym. J.; 2007, 16, 147.

5. Sarem, M.; Moztarzadeh, F.; Mozafari, M.; Shastri, V. P.; Mater. Sci. Eng. C. Mater. Biol. Appl.; 2013, 33, 4777.

6. "Cockerill FR, Clinical Institute LS. Performance standards for antimicrobial disk susceptibility testing: approved standard," Natl. Comm. Clin. Lab. Stand., 2012.

7. Gholipourmalekabadi, M.; Bandehpour, M.; Mozafari, M.; Hashemi, A.; Ghanbarian, H.; Sameni, M.; Salimi, M.; Gholami, M.; Samadikuchaksaraei, A.; Burns, 2015.

8. E. L. Silva, S. M.; Braga, C. R.; Fook, M. V.; Raposo, C. M.; Carvalho, L. H.; \& Canedo; Application of infrared spectroscopy to analysis of chitosan/clay nanocomposites. 2012.

9. Zhuang, H.; Zheng, J. P.; Gao, H.; De Yao, K.; J. Mater. Sci. Mater. Med.; 2007, 18, 951.

10. Gholipourmalekabadi, M.; Nezafati, N.; Mozafari, M.; Samadikuchaksaraei, A.; Hajibaki, L.; Moztarzadeh, F.; Hesaraki, S.; IET Nanobiotechnology; 2015.

11. Bellantone, M.; Williams, H. D.; Hench, L. L.; Antimicrob. Agents Chemother:; 2002, 46, 1940.

12. Hughes, S. P. F.; J. Hosp. Infect.; 1988, 11, 41. 